\title{
The status of some herbaceous species populations in West Siberian subtaiga forests
}

\author{
Elizaveta Komarevtseva*, Natalia Kurochkina, and Natalia Gordeeva \\ Central Siberian Botanical Garden of the SB RAS, 630090 Novosibirsk, Russia
}

\begin{abstract}
The coenopopulations of Bupleurum longifolium L., Pulmonaria mollis Wulf. ex Hornem., Angelica sylvestris L were studied in the territory of the experimental forest park of CSBG (Novosibirsk). The coenopopulations have a left-sided spectrum. The main method of reproduction of species - seed. In the intact pine-birch forest, coenopopulations of species with a low density of individuals develop. In weakly disturbed habitats (selective felling, periodic haying) the densities of individuals in B. longifolium, $P$. mollis increases, as well as old (in $B$. longifolium) or juvenile (in A. sylvestris) individuals fall out. Improving lighting here causes an increase in the size parameters of generative individuals and the acceleration of their development.
\end{abstract}

To estimate vegetation wellbeing of specially protected natural object «Central Siberian Botanical Garden (CSBG SB RAS)», coenopopulations of Bupleurum longifolium L., Pulmonaria mollis Wulf. ex Hornem., Angelica sylvestris L were investigated in JulyAugust 2018. These species are widespread in small-leaved and light-coniferous subtaiga forests of West Siberia $[1 ; 2]$. To reveal the status of coenopopulations these species, their ontogenetic structure and peculiarities of the development of generative plants in various growing conditions were studied.

The ontogenesis was described: B. longifolium [3; 4], P. mollis [5], A. sylvestris [6]. Structure of coenopopulations was studied according to the common technique $[7 ; 8]: 10$ 42 plots of $1 \times 1 \mathrm{~m}^{2}$ were set; specimens of each ontogenetic state were counted. The number of plots depended on the abundance of species in the cenosis. 10-25 generative individuals were examined at coenopopulations to identify developmental features.

Forest Park of the CSBG is situated on right bank of Ob' river. Pine-birch forests are the background forest type; most of territory is intact, but some sites are subjected to selective tree felling or are crossed by country roads. We choose three sites. The first site (site 1) is located in intact pine-birch herb forest: cover of Betula pendula Roth is $60 \%$, Pinus sylvestris L. is $5 \%$. Total cover of herbs is $80 \%$ : Pteridium aquilinum (L.) Kuhn (40\%) and Aegopodium podagraria L. (10\%) are dominate. Grass cover is made by Brachypodium pinnatum (L.) Beauv. and Carex macroura Meinsh. In this site, a study was conducted on all species with a low coverage here: B. longifolium $-5 \%$, A. sylvestri $-1 \%$, P. mollis $-1 \%$. The other two sites are exposed to anthropogenic influence. The second site

${ }^{*}$ Corresponding author: elizavetakomarevceva@yandex.ru 
(site 2) situated on the edge of grass birch forest, subjected to selective felling: cover of Betula pendula is 50\%. Grasses prevail: Brachypodium pinnatum (12 \%), Dactylis glomerata L. (7 \%), Calamagrosti arundinacea (L.) Roth (7 \%), Carex macroura (12\%). Herbs have a little less cover: Aegopodium podagraria-12\%, Heracleum dissectum Ledeb. $-10 \%$, P. mollis-10\%, Veronica chamaedrys L. $-5 \%$. With the exception of $P$. mollis, the cover of the studied species is low (1-2\%). On this site we studied P. mollis and B. longifolium. The third site (site 3 ): forest meadow with shrubs is located next to country road, the edges of which are periodically mowed. The shrub layer is composed of Salix cinerea L. (25\%) and juvenile Tilia cordata Mill. (15\%). Total herb cover is $80 \%$, cover of grasses is low (10\%): Dactylis glomerata (5\%), Carex macroura (3\%), Poa angustifolia L. (3\%). Veronica chamaedrys (30\%), Aegopodium podagraria (20\%), A. sylvestris (20\%), Filipendula ulmaria (L.) Maxim (10\%) dominate in herb layer. Cirsium helenioides (L.) Hill (5\%) and C. setosum (Wild.) Bess. (2\%) indicate anthropogenic influence. On this site we studied A. sylvestris; B. longifolium and $P$. mollis were not abundant (1-3).

B. longifolium, P. mollis belong to semirosette short-root polycarpics. Individuals of species have a complex ontogenesis, in which the seed individual (genet) is divided into several daughters (ramets). Fragmentation (disintegration) of individuals occurs in the generative state. It is accompanied by a shallow rejuvenation of ramet in B. longifolium [3]. In $P$. mollis ramet rejuvenation does not occur, the formed particulates (ramets) quickly age and pass into the old generative state [5]. Both species form an implicit polycentric life form with non-specialized complete disintegration $[9 ; 10]$. A. sylvestris is a perennial monocarpic plant. During simple ontogenesis (vegetative reproduction is absent) the species develops a monocentric biomorph. Regardless of the ability to vegetative reproduction, resumption of coenopopulations in all three species occurs by seed. So their coenopopulations here have left-sided spectrum (Fig. 1).

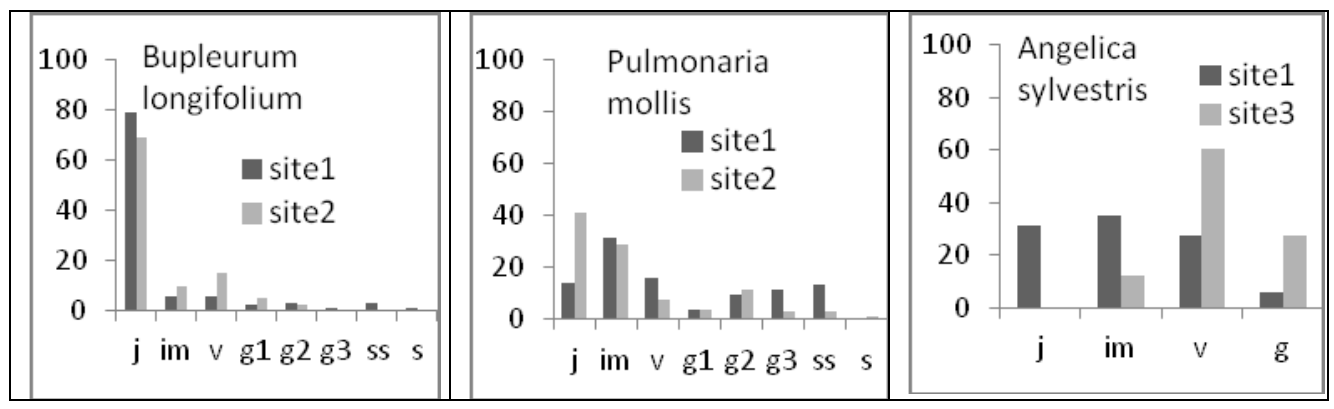

Fig. 1. Ontogenetic spectra of species. On the X-axis- ontogenetic states; on the $\mathrm{Y}$-axis - the percentage of individuals.

In the spectra of $B$. longifolium is dominated by juvenile individuals (68.8-79.4\%). Immature $(\mathrm{im})$ and adult vegetative $(v)$ plants are represented much less: $(5.6-9.5 \%)$. The presence of all generative individuals is also insignificant: from $6.1 \%$ to $13 \%$. All this testifies the effective seed renewal of this species in forests regardless of the degree of habitat disturbance. A selective felling in the birch forest (site 2) causes the loss of old generative $\left(g_{3}\right)$ and post-generative individuals $(s s, s)$, as well as an increase in seedlings (up to 24 pieces $/ \mathrm{m}^{2}$ ). As a result, the density of coenopopulation increases to $21.3 \mathrm{PCs} / \mathrm{m}^{2}$ compared to the 1 st site $\left(16.8 \mathrm{PCs} / \mathrm{m}^{2}\right)$.

Habitat conditions significantly affect the development of generative plants. Adult individuals $B$. longifolium form shoots of different cyclicity: monocyclic (annual) and polycyclic (2-5-year). In the dark coniferous forests of Salair monocyclic shoots develop in middle-aged generative individuals $\left(g_{2}\right)$, polycyclic shoots - mainly in young $\left(g_{l}\right)$ and old 
$\left(g_{3}\right)$ generative [4]. In the forest Park of CSBG monocyclic generative shoots develop in young and mature generative $\left(g_{2}\right)$ states. At the end of the generative period, mainly di and tricyclic (2-3-year) shoots are formed. Monocyclic shoots develop only from the renewal buds on the basal part of the shoot, and di- and tricyclic shoots - often from dormant buds on the rhizome. There is an increase in the number of monocyclic shoots in individuals at the edge of the birch forest ( $52 \%$ of the total number of generative shoots) compared with the pine-birch forest (39\%). Comparison of morphological parameters of generative individuals from coenopopulations showed that at the edge (site 2), in better light individuals $B$. longifolium are large in size: the length of the shoot is an average of $124.6 \mathrm{~cm}$, its weight $-4.8 \mathrm{~g}$. In undisturbed forest (site 1) these parameters below: $119 \mathrm{~cm}$ and $3.4 \mathrm{~g}$. This allows concluding that an improvement in the light regime has a positive effect on the development of $B$. longifolium. At the population level, this is expressed in an increase in the number of seedlings and the density of coenopopulation, and at the organizational level - in reducing of the generative shoot cyclicity and increasing its size.

Coenopopopulations of $P$. mollis have a left-sided spectrum: the main maximum is formed on juvenile or immature plants, the 2 nd maximum - on adult or old generative. In the birch forest (site 2 ) the maximum on juvenile individuals $(41.2 \%)$ is due to the active settling of the species at partial felling of forest areas: up to 13 seedlings per $1 \mathrm{~m}^{2}$. The majority of young vegetative individuals $(j, \mathrm{im})$ are eliminated at the transition to the next age state $(v-7.3-16.1 \%)$. The increase in seedlings and juvenile individuals $(\mathrm{j})$ under disturbed grass causes a significant density of coenopopulations of $P$. mollis in birch forest (site 2) to 20.6 PCs $/ \mathrm{m}^{2}$ compared with pine-birch (site 1: $3.4 \mathrm{PCs} / \mathrm{m}^{2}$ ).

Morphological parameters of mature generative individuals of $P$. mollis change in different communities. At the edge of the birch forest (site 2) flowering plant consists of 15 rosette and 1-6 generative shoots length 19.5-56.5 $\mathrm{cm}$. In pine-birch forest (site 1) generative plant has 1-4 rosette and 1-4 generative shoots reaching a length of 11.5-49.5 $\mathrm{cm}$. This leads to a noticeable difference in the above-ground mass of one plant: in the birch forest up to $14.7 \mathrm{~g}$ and in the pine-birch - up to $6.6 \mathrm{~g}$. But most significantly differ in plants by mass of rhizomes. In the birch forest in disturbed cutting areas is the development of powerful rhizomes in mature generative individuals: diameter up to $1.5 \mathrm{~cm}$ and weight up to $24 \mathrm{~g}$. Rhizomes are thinner (up to $0.8 \mathrm{~cm}$ ), their weight reaches up to $4.2 \mathrm{~g}$. in the pinebirch forest. The development of the generative part of the plant is the same in both habitats. The formation of powerful rhizomes allows the species to keep its territory in disturbed habitats. In addition, there is a slight acceleration in the development of the apical bud of the rosette shoot. So in the pine-birch forest in the apical bud there are 3-4 leafy rudiments in mid-June, in a birch forest up to 6 rudiments and in a few cases even the rudiments of the generative. It should be noted that in the pine-birch forest, many apical buds are damaged by larvae of the May beetle and the next year the elongated shoots of them will not develop, and this will cause a break in the flowering of many generative individuals. So, coenopopopulations of $P$. mollis have a left-sided spectrum. In the pinebirch forest, less developed individuals form; possible breaks in flowering due to damage to the apical buds rosette shoot larvae of the May beetle. On the edge of the birch forest increases the efficiency of seed renewal species, the rate of development of individuals slightly accelerated, as well as forming powerful rhizomes in generative plants, which allows the species to keep the territory.

A. sylvestris develops during simple ontogenesis, which ends in a generative state. The left-sided spectra of $A$. sylvestris are characterized by the absence of old non-flowering ( $s$, $s s$ ) plants due to its monocarpicity. Ontogenetic spectra of coenopopulations differ in the position of the maximum, the proportion of generative plants, and the degree of completeness. So in the pine-birch forest cenopopopulations are full-range (all ontogenetic groups are included), it is dominated by immature individuals $(35.2 \%)$ with a small 
number of generative $(5.9 \%)$. On the bushy forest meadow, near the country road (site 3), the peak falls on adult vegetative plants $(60.3 \%)$, and significantly more generative individuals (27. $6 \%$ ) in the complete absence of juvenile. Probably, due to the mowing, the generative individuals do not have time to get disseminated, and as a result a juvenile group falls out. About haymaking evidence we found stumps of cut last year's generative shoots A. sylvestris. Differences in the spectrum do not affect the density of the species (3-3.6 $\mathrm{PCs} / \mathrm{m} 2)$. The greatest development is reached by generative individuals in the bushy forest meadow (site 3). The average values of the basic morphological parameters of flowering plants are higher here, which is explained by the best lighting with sufficient soil moisture.

Thus, in the Forest Park of the CSBG the coenopopulations of Bupleurum longifolium, Pulmonaria mollis and Angelica sylvestris are in a satisfactory condition in the intact and slightly disturbed habitats. Coenopopulations of the species have a left-sided spectrum, which is due to the predominance of seed renewal in them. Normal full-range cenopopulations with a low density of individuals develop in the bracken-grass pine-birch forest (an intact site). Growth in habitats with a small anthropogenic impact (selective felling, periodic mowing) increases the efficiency of seed renewal in B. longifolium, $P$. mollis, which causes an increase in the density of cenopopulations of these species due to pregenerative plants $(j, \mathrm{im})$. But at the same time, it is possible the loss of old $(B$. longifolium) or juvenile (A. sylvestris) plants from the coenopopulations. Habitat conditions significantly affect the development of generative individuals of these species. Lighting improvement while maintaining sufficient soil moisture in slightly disturbed habitats contributes to the increase in the size characteristics of adults in all three species. In $P$. mollis and A. sylvestris, an increase in the biomass of above-ground part of plants is also observed by 1.5-2 times, which causes and increase in the coverage of these species to 10 $20 \%$ in slightly disturbed cenoses. In addition, under these conditions, there is acceleration in the rate of development of adult individuals. In B. longifolium, this is expressed in an increase in the number of monocyclic shoots in generative individuals, in $P$. mollis - in the formation of a larger number of rudiments in the apical bud of the rosette shoot.

\section{References}

1. M. Pimenov, Flora of Siberia, 10 (1996)

2. O. Nikiforova, Flora of Siberia, 11 (1997)

3. L. Vasilyeva, N. Lashchinsky, Plant resources, 3 (1987)

4. E. Podgaevskaya, Ontogenetic atlas of plants, 3 (2002)

5. T. Petrova, Ontogenetic atlas of plants, 3 (2002)

6. E. Vinokurova, Terpenoids in ontogenesis Angelica sylvestris L. in dark coniferous forests of Salair (Barnaul, 2013)

7. A.A. Uranov, Biol. Nauki, 2 (1975)

8. O. Smirnova Cenopopulations of plants (principal concepts and structure) (M, Nauka, 1976)

9. L. Gatzuk., O. Smirnova , L. Zaugolnova, L. Zhukova, J. Ecol., 68 (1980)

10. O. Smirnova, M. Palenova, A. Komarov, Russian J. of Developmental Biology, 33 (2002) 